\title{
The Impact of Metacognitive Strategies on Jordanian EFL Learners' Writing Performance
}

\author{
Tamer Mohammad Al-Jarrah ${ }^{1}$, Noraien Mansor ${ }^{1} \&$ Radzuwan Ab Rashid ${ }^{2}$ \\ ${ }^{1}$ Universiti Malaysia Terengganu, 21300 Kuala Nerus, Terengganu, Malaysia \\ ${ }^{2}$ Universiti Sultan Zainal Abidin, 21300 Kuala Nerus, Terengganu, Malaysia \\ Correspondence: Radzuwan Ab Rashid, Faculty of Languages and Communication, Universiti Sultan Zainal \\ Abidin, 21300 Kuala Nerus, Terengganu, Malaysia. E-mail: radzuwanrashid@unisza.edu.my
}

Received: April 16, 2018 Accepted: June 27, 2018 Online Published: November 26, 2018

doi:10.5539/ijel.v8n6p328 URL: https://doi.org/10.5539/ijel.v8n6p328

\begin{abstract}
One of the most challenging aspects of foreign language learning is writing. Writing is the most demanding and complicated aspect of language system. Writing requires the collective effort of orthographic, graphomotor and other linguistic skills with the inclusion of semantics, syntax, spelling, and writing conventions without being restricted to the aforementioned skills. The Improvement of cognitive psychology, metacognition has drawn the focus of an increasing number of researchers' and paved way for recent dimensions on EFL writing, particularly in the aspect of writing achievement. Due to the fact that the method possesses a highly-placed executive aptness which comprises of formulation, supervision, and assessment, this study attempts to investigate the influence of using metacognitive strategies on Jordanian EFL learners' writing performance. Forty four students were randomly selected from secondary school level to partake in experimental control of the study. The researcher made use of the intervention program based on CALLA model of teaching in classroom. The experimental group (EG) received metacognitive strategies-based writing instruction whereas the control group (CG) received only the routine writing instruction (Product Approach). After five weeks of instruction, both groups were post-tested and at the end of program which lasted for twelve weeks, the students carried out another post-test. Data were submitted to the independent Mann-Whitney U test followed by Wilcoxon Signed-Rank test analysis. The results showed that there was a positive effect in the experimental group's writing performance. The findings of this study have implications for pedagogy as well as for future research.
\end{abstract}

Keywords: metacognitive strategy, writing performance, EFL, cognitive

\section{Introduction}

Writing well is really a big challenge for both native and non-native students (Muslim, 2014). However, writing in English has become an important skill in Arab countries though it is more complex for Arab students (Al-Bahrani, 2014). It is a foreign language for Arab students, which is quite different from their first language. Similarly, due to the fact that writing is an intricate and complex task, it is the most difficult of all skills abilities to acquire. However, using English to write among Arab students is challenging. They are more prone to committing errors (Muthanna, 2016; Mohammed \& Rashid, 2017). Hence, Arab learners of English which include Jordanian encounter major problems in writing skills. This problem has been discussed by researchers such as (Salem, 2012). The major challenge towards effective writing among the Arab students and Jordanians in particular centers on lack of ideas in coherent and cohesive manner (Mugableh \& Ibrahim, 2016; Bani-Khaled, 2013).

The task of emerging a skillful writer does not only depend on possessing the required knowledge and skills needed in the field, but also the metacognitive cognizance. Goh and Taib (2006) founded the term metacognition to depict the knowledge and awareness of the cognitive process, of cognitive strengths and shortcomings, and self-control that learners channel to a task. Since writing is such a complicated task, it takes into cognizant how a writer manages to encircle and handle all the tasks as an evidence of metacognitive and self-regulatory knowledge and strategies (Mohamed \& Rashid, 2017a). Proficient writers use metacognitive awareness and knowledge during each phase of the writing process. Skillful writers have a well-grounded executive or control structure which examines and build the entire writing process whilst proficient writer access their writing 
performance through mediation (Amani, 2014). By engaging in self-talk, one mediates his/her own thought process during the stages of writing.

All writers take a run at writing processes with a little metacognitive knowledge. Studies by Gustilo (2013), Wei et al. (2012) have revealed that "all writers (L1 and L2) could be categorized as possessing a metacognitive knowledge which adds up to their cognitive type of writing process" and which later on has effects on the performance of the writers on the written tasks. Various studies (e.g., Bitchener et al., 2005) have discovered the relationship between the point to which students adopt metacognitive strategies and their writing performance. Ashman and Conway (2017) suggest that students require strategies, both cognitive and metacognitive, designed for them by a teacher as well as knowledge regarding the types of strategies available, the "circumstances surrounding the usage of these strategies are most helpful and a fundamental reason why one may desire to use them as one method which can aid the advancement of metacognitive knowledge" (p. 199). Another way is to give the students longer hours of constant mastering and awareness which alongside "perform a vital part in the building up of metacognitive knowledge and regulatory skills" (p. 201).

A study by Shazia (2014) though finite in sample size, discovered a strong relationship between metacognitive reflection and achievement among Jordanian ESL students. In the study, students with huge progress attended more in subsequent reading, correction and accessment (i.e. in metacognitive processes) than students with low achievement. Downing et al. (2007) found out that the usage of reflective journals before and after the actual writing is "useful for stimulating and multiplying the students' awareness of proficiency in writing skills and is largely connected to writing performance" (p. 4). Further studies have portrayed the worth of reflective tasks in arousing students to meet the demands of writing for specific discourse communities (Hirvela, 1997). A substantial number of studies, reviewed by Lopera Medina (2012) reported huge impact in the specific use of the cognitive strategy taught in classrooms (e.g., Graham \& Perin, 2007; Garner \& Hare, 2006; Powell \& Kalina, 2009). Overall, these studies support Zumbrunn et al. (2011) statement: "Students who master writing strategy training make progress in the quality of what they write" (p. 12).

Metacognition is defined by Downing et al. (2007) as "second-order cognitions: thoughts about thoughts, knowledge about knowledge, or considerations about actions" (p. 8). It is distinguished from cognition "in that cognitive skills those are vital to carry out a task, while metacognition is paramount to comprehending the way task was carried out (Beauchamp \& Kennewell, 2010, p. 762). In a sentence, "metacognition is the control of cognition. That is, learners have to connect these metacognitive skills with their strategic knowledge about what they are aware of (declarative), how to put the knowledge to use(procedural), and what period and the reason they can utilize the knowledge (conditional)" (Hong-Nam \& Leavell, 2006, p. 407). To show this concept, Pittinsky (2008) enumerated a study in which preschool and basic school children learn a group of items until they felt they have the ability to recollect them flawlessly. Older children displayed signs of being ready when they portrayed "perfect recall", while the younger children normally do not. These findings implied that "young children have finite knowledge and cognition about cognitive phenomena or in their metacognition" (p. 52).

Learning to write particularly in a foreign language is extremely important for learners of foreign language. It has been peak of the process through which the students' performance in almost all aspect is evaluated. Diverse communications in academic life are challenged through writing as a means of communication. Taking into consideration the objective to grasp the entire picture of the complex nature of written composition, this study is targeted at investigating the efficiency of metacognitive strategies based on CALLA Model in improving the writing performance of EFL learners among final year high school students. As depicted in chapter two of this study, metacognition is focused on the awareness and control of one's mind and thinking processes. In a nutshell, metacognitive strategies are those processes which anticipate the learners to reflect upon their own reasoning when they partake in academic tasks. The significance of metacognitive strategies and prominence of using CALLA model are justified in this study.

\section{Literature Review}

\subsection{Metacognitive Strategies and Teaching EFL Writing Metacognitively}

Students hardly write and virtually everything they write is within the sphere of the classroom. The most vital tool in writing activities is that students need to be active in order to make the learning process of immense importance (Chutichaiwirath \& Sitthitikul, 2017). Encouraging the student to take part in the exercise, at the same time improving performance and increasing writing proficiency requires a certain pragmatic approach. The teacher should be crystal clear on what skills he/she is attempting to improve. Secondly, the teacher needs to select a pattern (or type of exercise) can aid learning in in the desired field. Once the target areas and means of execution are stated, the teacher can forge ahead to focus on what topic can capture the students' attention and 
ensure their participation. By pragmatically putting together these objectives, the teacher can anticipate both zeal and a viable learning (Danielson, 2013).

Metacognition performs a key role in improving writing performance. Research on metacognition has shown that less efficient learners do not identify the purpose of writing and channel their attention on word-by-word writing rather than writing performance for the task (Collins et al., 1989; Mohamed \& Rashid, 2017b). Taggar and Neubert (2008) add that poor writing performers have longed finish writing the passage unaware that they have not comprehended the passage. In addition, poor writing performers are hardly able to improve their performance rate to fit the aim of writing (Woods, 2006). When they fail to grab the test, poor writers are not as pliant as a proficient writer in using different strategies to counter the problem (Knapp \& Watkins, 2005; Corkery, 2014).

Metacognitive strategies have been apprehended as a characteristic of a perfect response to eradicating in general (Hertzog \& Dunlosky, 2004) as well as of expert writing (Flower, 1989; Flavell, 1979). Proficient writers are more aware of what they write, they make more decisions about planning and controlling as they write and they are more likely to self-evaluate their writing as they are more proficient than inefficient writers. To ascertain the role of metacognitive strategies in writing, it is necessary to take into consideration the relationship between cognitive and metacognitive strategies that a strategic writer employs. An efficient writer uses a wide range of cognitive strategies for accomplishing the writing tasks. Cognitive strategies have been created to assist learners to achieve their cognitive goal (Flavell, 1979). Examples of cognitive strategies for writing might include brainstorming ideas, creating an outline, doing the prewriting, writing the first draft, writing sound sentences or proofreading for grammatical errors. Contrary to cognitive strategies, metacognitive strategies have been designed to assess cognitive progress. Student writers employ metacognitive processes or strategies to plan their engagement in the writing process (Harris, Graham, \& Mason, 2003).

Although extrinsic guidance and support can help learners in carrying out literacy skills, self-questioning and self-monitoring are assumed to be more effective in aiding language learners to plan, oversee and assess their reading and writing processes (Penuel et al., 2009). When EFL writing instructors have a large class as the instructors in Jordan do, training students to become contingent learners who possess metacognitive strategic knowledge for writing and for assessing their own writing should be resourceful to tackle some of the issues posed by the large class size and to develop students' writing proficiency. This paper, therefore, encourages EFL writing instructors to teach for meta-cognition so as to improve and enhance students' metacognitive models and awareness with Jordanian students. Briesmaster and Etchegaray (2017) conducted an empirical study to bring forth teaching principles of EFL writing. The study supports Flavell's (1979) theoretical structure of metacognition which comprises of metacognitive knowledge and metacognitive experiences and produced important pedagogical implications for researchers.

\section{Methodology}

This research involved 44 EFL students who were in the last year of secondary school of Al-Mazar Irbid in Jordan. They were at the secondary school level. Their language proficiency was determined by holistic scoring by two researchers. The class met for about two hours every week for 12 weeks. In this study, there were various instruments used which included, pre-test, immediate post-test, and delay test. The test question was given from the course materials that assumed as the source book of their current study.

Since the students had been placed in two different interactive classes in advance by their educational program, one class was assigned as the control and the other as the experimental group. The experimental group (EG) received metacognitive strategies-based writing instruction whereas the control group (CG) received only the routine writing instruction (Product Approach). After five weeks of instruction, both groups were immediately post-tested. Also, both groups receive the delay post-test at the end of instruction program week twelve. Data were submitted to Mann-whiny $\mathrm{u}$ test followed by Wilcoxon signed-rank test analysis to measure the effectiveness of metacognitive strategy on writing performance among EFL learners. The pretest of a writing performance was given to all participants in this study. The students were tasked to write on a topic with about 150 words in an essay format. Then, the instruction on the metacognitive learning strategies for the experimental group was considered in 40 minutes. This strategy was made up of five stages based on CALLA model (Cognitive Academic Language Approach) by Chamot and O'Malley (1994) and they were as follows:

Preparation: In the phase of preparation, the researchers first assist the students to associate what they know about the contents and strategies, what missing gaps in prior knowledge that needs to be tackled. Detailing, advance organization and selective attention are frequently taught and practiced in this stage. Then the teacher 
proposed metacognitive writing strategies to students and expound the how paramount it is and help the students to set positive, realistic goals.

Presentation: In this phase, the metacognitive strategies in writing were brought forth and elaborated to students in English which were backed by contextual clues. The researchers first gave out a list of the metacognitive strategies in writing including self-preparation, self-monitoring and self-assessment. Then, the features, usage, and applications of the strategy were vividly elaborated using examples.

Practice: The students were given the privilege of practicing new strategies with original writing activities in this stage. They were expected to recollect writing strategies including cognitive and metacognitive method that were displayed in the presentation stage; then students began to plan their writings according to self-planning strategy.

Evaluation: In this phase, students were asked to assess the stage of their writings so that they could effectively comprehend what they had grabbed about new strategies, skills and what is essential for re-assessment. Self-assessment activities encompasses self-questioning; debriefing discussions after strategies practice; learning blogs in which students recorded the feedback of their learning strategies applications; checklists of strategies used; and open-ended questionnaires where students can express their opinions about the prominence of any distinct strategies. We carried the assessment activities through three stages: self-evaluation done by the students, peer-evaluation which is done by classmates and teacher evaluation which is done by the teacher.

Expansion: This phase gives the participants with platform to utiliz their intellect (Chamot \& O'Malley, 1990). In this phase, students were motivated to use the strategies that they feel will be most effective; to move current strategies to a distinct context; and to create their own individual combinations and interpretations of metacognitive strategies. This phase sets out to assist students to practice, combine, evaluate, estimate and incorporate the strategies that they just learned which primarily included self-planning, self-monitoring and self-evaluation.

Writing Tests: All participants from the experimental and control groups were expected to take one pre-test and one post-writing a test to assess whether there was an improvement in writing performances over several weeks of training in the research. The test provided data for measuring participants' writing performance. A pretest was conducted before the experiment to ascertain that the writing abilities of the two classes were moving at the same speed. The topic list of the writing task is chosen to show the rate of participants' performance indifferent elements of paragraphs.

\section{Result}

Table 1. Descriptive statistics: general writing proficiency

\begin{tabular}{llllll}
\hline & Group & N & Mean & Std. Deviation & Std. Error \\
\hline Pre-test & +MST (Exp.) & 22 & 12.50 & 1.045 & .158 \\
& -MST (Contr.) & 22 & 12.10 & 1.649 & .249 \\
& Total & 44 & & & .368 \\
& + MST (Exp.) & 22 & 17.75 & 2.441 & .270 \\
\hline Immediate Post-test & -MST (Contr.) & 22 & 14.77 & 1.790 & .358 \\
& Total & 44 & & & .198 \\
\hline Delayed Post-test & + MST (Exp.) & 22 & 20.36 & 2.373 & 1.317 \\
& -MST (Contr.) & 22 & 13.82 & & \\
\hline
\end{tabular}

Note. +MST: Plus Metacognitive signified experimental groups, -MST: Minus Metacognitive signified Control groups.

Table 1 above presents the descriptive statistics on the overall scores of general writing proficiency of the participants in both groups. The result showed the mean value of the overall scores of the participants in + MST group and -MST group in the pre-test, immediate post-test and delayed post-test. The overall scores of the participants are reported based on the means, standard deviation, and standard errors. In the pre-test the results showed that $(\mathrm{M}=12.50, \mathrm{SD}=1.045, \mathrm{SDE}=.158)$ for the experimental group $(+\mathrm{MST})$ and $(\mathrm{M}=11.55, \mathrm{SD}=1.649$, $\mathrm{SDE}=.249$ ) for the control group (-MST). Simply, the results showed that the mean scores of two groups are not meaningfully different according to their performance in writing composition at the beginning of the study.

Moreover, at the intermediate stage where another test was given to the participants (intermediate post-test), the results obtained from experimental group are illustrated as $(\mathrm{M}=17.75, \mathrm{SD}=2.441, \mathrm{SDE}=.368)$ while for the 
control group (-MST) the result showed $(\mathrm{M}=14.77, \mathrm{SD}=17.90, \mathrm{SDE}=.270)$. Meanwhile, the results obtained from the delayed post-test which was conducted at the end of the intervention program are reported as $(M=20.36$ $\mathrm{SD}=2.373, \mathrm{SDE}=.358)$ for $+\mathrm{MST}$ group (experiment group) and $(\mathrm{M}=13.82, \mathrm{SD}=13.17, \mathrm{SDE}=.198)$ for $-\mathrm{M}$ group (control group). Consequently, the results obtained through immediate post-test and delayed post-test as presented above showed that there is difference in the mean scores between the groups of the participants.

The Mann-Whitney $U$ test was conducted to determine the effects of metacognitive strategies on the overall performances of the participants. Because the scores were non-normally distributed, the Mann-Whitney $U$ test the nonparametric counterpart of one-way independent ANOVA was used in order to specify whether there is any possible difference between the performances of both experimental and control groups at the beginning and the end of the program. And Wilcoxon Signed-Rank test was used to examine the differences in the performances from within the group participants.

Table 2. Between-group overall score of pre-test

\begin{tabular}{lllllll}
\hline Group & $\mathrm{N}$ & Mean Rank & U value & z value & p value & r value \\
+ MST (Exp.) & 22 & 26.48 & 154.500 & -2.185 & .001 & -0.333 \\
\hline -MST (Cntr.) & 22 & 18.52 & & & & \\
Total & 44 & & & & & \\
\hline$* P<0.01$. & & & & &
\end{tabular}

$* \mathrm{P}<0.01$

In order to establish the homogeneity of the two groups in terms of their overall performance in writing, the Mann-Whitney U test, was carried out. As illustrated on Table 2, the Mann-Whitney U test has indicated that here was no significant difference in the overall score of the pre-test between $+\mathrm{MST}$ and $-\mathrm{M}$ groups $(\mathrm{U}=$ $154.500, \mathrm{z}=-2.185, \mathrm{p}=.001, \mathrm{r}=-0.333)$. The mean values score margin between the two groups is not reasonable. Meanwhile, the effect size of $r=-0.333$ which indicates a small effect. Therefore the $r$ value was an indicator that effect between the two groups is not a considerable one considering the threshold of Cohen's benchmark of large effect size.

Table 3. Between-group overall scores of immediate post-test

\begin{tabular}{lllllll}
\hline Group & $\mathrm{N}$ & Mean Rank & U value & z value & p value & r value \\
+ MST (Exp.) & 22 & 30.30 & 70.500 & -4.121 & .000 & -0.6285 \\
\hline -MST (Cntr.) & 22 & 14.70 & & & & \\
Total & 44 & & & & & \\
\hline
\end{tabular}

$* \mathrm{P}<0.01$.

Table 3 presents the results obtained from the immediate post-test. This test was conducted to examine if there is a significance difference between the group that received metacognitive instructions (Experimental group) and group that did not received metacognitive instruction (control group) at the intermediate stage of the training program. Also the Mann-Whitney U test was utilized here to illustrate the effect size of the differences. The results revealed that there was a significant difference in the overall scores of the immediate post-test between $+\mathrm{MST}$ and $-\mathrm{M}$ groups $(\mathrm{U}=70.500, \mathrm{z}=-4.121, \mathrm{p}=0.000, \mathrm{r}=-0.6285)$. The difference observed in the mean rank value though comparing the two groups' performance revealed that the difference was significant. Meanwhile, the $r$ value $(r=-0.6285)$ showed that the effect was a medium to a large.

Table 4. Between-group overall scores of delayed post-test

\begin{tabular}{lllllll}
\hline Group & $\mathrm{N}$ & Mean Rank & U value & z value & p value & r value \\
+ MST (Exp.) & 22 & 30.45 & 67.000 & -4.167 & .000 & -0.6355 \\
\hline -MST (Cntr.) & 22 & 14.55 & & & & \\
Total & 44 & & & & & \\
\hline$* \mathrm{P}<0.01$. & & & & &
\end{tabular}

The delayed post-test was the final test administered to both + MST and $-\mathrm{M}$ groups. The aimed of conducting this test was to examine the impact of using metacognitive strategies on the experimental group, and its effects on the writing performances of EFL students. Table 4 presents the results obtained from the delayed post-test. 
The Mann-Whitney $\mathrm{U}$ test results revealed that there is a significant difference in the performance between + MST and $-\mathrm{M}$ groups $(\mathrm{U}=67.000, \mathrm{z}=-4.167, \mathrm{p}=0.000, \mathrm{r}=-0.6355)$. Henceforth, by comparing the mean rank value between the performance of the two groups, it was found that the difference was significant (+MST group $\mathrm{m}=30.45$, while $-\mathrm{M}$ group $\mathrm{m}=14.55$ ) the wide margin between two mean groups was an indicator of impact of the metacognitive instructions received by the experimental group (+MST) on over control group (-MST) who did not received such treatment during the course of conducting this study. Meanwhile, the $r$ value $(r=-0.6355)$ showed that the effect was a medium to a large.

In order to ascertain whether the changes exhibited by groups in response to the treatment over time were statistically significant, the Wilcoxon signed-rank test, the non-parametric Counterpart of dependent t-test was used. Data based on the overall scores of +MST group and -MST group were analysed separately using the Wilcoxon Signed-Rank test. First of all the overall performance of +MST group was analysed by comparing their scores in pre-test with that of immediate post-test scores as presented in Table 5. Similarly, the results presented in Table 6 showed the difference between the scores of pre-test compared with post-test from within the experimental group (+MST).

In the same vein, Wilcoxon Signed-Rank test was also used to measure the performance of the participants in the control group by comparing their overall scores in the pre-test with that of immediate post-test as well as comparing pre-test and delayed post-test. The aim of conducting this analysis was to examine the effect of changes observed as result of teaching students although, without metacognitive strategies instructions. The results of the writing in two groups were compared by using independent sample t-test statistical procedure.

Table 5. Within-group overall scores of +MST group (pre-test with immediate post-test)

\begin{tabular}{|c|c|c|c|c|c|}
\hline & $\mathrm{N}$ & $\mathrm{T}$ value & $\mathrm{z}$ value & $\mathrm{p}$ value & r value \\
\hline Before & 22 & 0.000 & -5.323 & 0.000 & -0.8118 \\
\hline After & 22 & & & & \\
\hline Total & 44 & & & & \\
\hline
\end{tabular}

The results of Wilcoxon Signed-Rank test in table 5 showed that there was a significant difference in the gain score of the experimental groups' performance in the pre-test $(T=0.00, z=-5.323, p=0.000, r=-0.8118)$ before and after metacognitive instruction. The results clearly showed that instruction with metacognitive strategies had a significant effect on the performance of the experimental students in their writing composition. The $p$ value $(\mathrm{p}=0.000)$ indicated that the relation is statistically significant. According the results +MST group made significant progress from the pre-test to the post-test. The effect size of $r=-0.8118$ represented a large effect on the students use of metacognitive strategies in writing within this group.

Table 6. Within-group overall scores of +MST group (pre-test with delayed post-test)

\begin{tabular}{llllll}
\hline & $\mathrm{N}$ & T value & $\mathrm{z}$ value & $\mathrm{p}$ value & $\mathrm{r}$ value \\
\hline Before & 22 & 0.000 & -5.375 & 0.000 & -0.8197 \\
After & 22 & & & & \\
Total & 44 & & & & \\
\hline
\end{tabular}

$* \mathrm{P}<0.01$

Table 6 demonstrates the results obtained by comparing the overall scores of the participants in the experimental group (+MST group) derived from within pre-test and delayed post-test. The Wilcoxon Signed-Rank test was also used to examine the difference in the gain score and to find the effect size metacognitive strategies on the writing composition performance of the experimental group. The results in the Table 6 show that $(\mathrm{T}=0.000, \mathrm{z}=$ $-5.375, \mathrm{p}=0.000, \mathrm{r}=0.8197$ ) before and after metacognitive instruction. The result clearly reveals that metacognitive instructions had a significant effects on the experimental students in their over scores in writing composition. The effect size of $r=-0.8197$ represents a large effect on the students use of metacognitive in writing.

However, the results presented in Table 5 and Table 6 above clearly reveal that there were statistically significant differences in performance of experimental group (+MST group) before the intervention treatment (pre-test) and after the intervention post-tests (immediate and delayed) $(p=.000>.001, p=.0000>.001(\mathrm{p}$ is 
significant at $1 \% \mathrm{p}=0.001)$. the effects of $\mathrm{r}$ value are $(\mathrm{r}=-0.8118, \mathrm{r}=-0.8197)$ which indicated a large effect. The also showed that experiment group participants had improved tremendously in the end of course. And that metacognitive instruction had a great impact on the writing performance of EFL learners at Jordanian secondary schools.

Table 7. Within-group overall score of -MST group (pre-test with immediate post-test)

\begin{tabular}{llllll}
\hline & $\mathrm{N}$ & T value & $\mathrm{z}$ value & $\mathrm{p}$ value & $\mathrm{r}$ value \\
\hline Before & 22 & 0.000 & -2.479 & 0.000 & -0.3780 \\
After & 22 & & & & \\
Total & 44 & & & & \\
\hline
\end{tabular}

$* \mathrm{P}<0.01$.

However, a similar analysis was run to examine if there is a significant difference in the gain score of the control group (-MST group) who did not receive metacognitive instruction. To achieve this Wilcoxon Signed-Rank test was utilized to compare between the gain score of -MST group before and after the treatment. Table 7 shows that there was a significant difference in the gain score of -MST students' performance in the writing composition performance $(\mathrm{T}=0.000, \mathrm{z}=-2.479, \mathrm{p}=0.000, \mathrm{r}=-0.3780)$. The result clearly shows that the teaching of writing using non-metacognitive instruction had also a significant impact on $-\mathrm{M}$ group performance in writing. The effect size of $r=-0.3780$ represents a small effect, thus indicating that the effect of non-metacognitive method can also improve the writing of EFL learners in Jordanian high schools.

Table 8. Within-group overall scores of -MST group (pre-test with delayed post-test)

\begin{tabular}{llllll}
\hline & $\mathrm{N}$ & T value & $\mathrm{z}$ value & $\mathrm{p}$ value & $\mathrm{r}$ value \\
\hline Before & 22 & 0.000 & -2.569 & 0.000 & -0.3918 \\
After & 22 & & & & \\
Total & 44 & & & & \\
\hline
\end{tabular}

$* \mathrm{P}<0.01$.

Table 8 reveals the difference between the gain score of $-\mathrm{M}$ group pre-test and post-test. The Wilcoxon Signed-Rank test was employed to examine if there were statistically significant differences from within $-\mathrm{M}$ group performance in writing composition. The results are presented as $(\mathrm{T}=0.000, \mathrm{z}=-2.569, \mathrm{p}=0.00, \mathrm{r}=$ -0.3918 ). The results clearly described that there is significant difference between the gain score of the $-\mathrm{M}$ group before and after the teaching period based on the design of this study. The effect size of $r=0.3918$ indicated a small effect while the $\mathrm{p}$ value is significant at $1 \%(0.001)$.

\section{Discussion}

Various studies have tried to specify the characteristics of good language learners and the type of strategies they use in a specific language task (Rahimi \& Katal, 2012). Some studies postulate that the effectiveness language learning can be determined by explicit use of different language tasks such as metacognitive knowledge about task characteristics and applying appropriate strategies for task solution (Azizi, Nemati, \& Estahbanati, 2017). Stracke (2016) points out the reasons why second language instructors recommend to use metacognitive strategies in EFL/ESL classroom. One of such reasons is the claim that metacognitive strategies enable learners to play active role in the process of learning, to manage and direct their own learning and eventually to find the best ways to practice and reinforce what they have learned (Rahimi, \& Katal, 2012). The results of this study show that there is a significant difference in the wide margin ( + MST group $\mathrm{m}=30.45$, while $-\mathrm{M}$ group $\mathrm{m}=14.55$ ) between two mean groups. The results indicate that the use of metacognitive instructions has effectively increased the performance of the experimental group (+MST) over control group (-MST) which did not receive such treatment during the course of conducting this study. However, the effect was a medium to a large as indicated by the $r$ value $(r=-0.6355)$. Moreover, the results obtained from the Wilcoxon Signed-Rank test clearly show that metacognitive instructions had significant effects on the experimental students in their overall scores in writing composition. The effect size of $r=-0.8197$ represents a large effect on the students use of metacognitive in writing.

Furthermore, the findings of this study agree with the results obtained by Javed (2013) in which the same CALLA model was adopted. Their study aims to investigate the effect of planning and monitoring as 
metacognitive strategies on Iranian EFL learners' argumentative writing accuracy. In Javed's study the results of T-Test indicated that there was a positive effect in the experimental group's writing performance. However, the subjects of this study where university students, but this finding also supported the findings of the study by Hartman (2015) where junior secondary school students were the subjects. Another thing to consider in their results is that they employed WebQuest theory to gather metacognitive strategies. In the similar vein Meyer (2015) points out that to become self-directed learners, students must learn to assess the demands of the task, evaluate their own knowledge and skills, plan their approach, monitor their progress and adjust their strategies as needed.

Moreover, a study close to the present one was conducted by Aliweh (2011) who investigated the effects of a proposed strategy-based writing model on Saudi EFL students' writing skills. Out of three classes from Al-kuds School, two male third-year intermediate classes were randomly assigned to the control group $(\mathrm{N}=32)$ or experimental group $(\mathrm{N}=33)$. Class (B), serving as a control group, were taught the course-book "Say It in English" in the traditional method, while Class (C), serving as an experimental group, were taught the same course-book, supplemented with the strategy-based writing model which included six types of strategies: cognitive, meta-cognitive, compensational, social, affective and multiple strategies.

Both groups were pre-post tested using a writing test prepared by the researcher. Two hypotheses were formulated and tested. Results obtained from T-test revealed that the strategy-based writing model was effective in enhancing the participants' writing skills. In addition, compared to the traditional instruction, the strategy-based writing model was more effective in improving the participants' writing skills. The results adduce the importance of implementing the strategy-based writing model in EFL classrooms as it enabled the participants to conceive writing as a recursive process which entails flexible and purposeful movement through the three stages of writing.

Another study which revealed a result that is in agreement with this postulation, was conducted by Johnson (1991) who claimed that metacognitive strategies could encourage success in learning and the use of individual learning contracts could enhance an individual's ability to become a more conscientious learner. Results indicated that the process helped students become more conscientious and more met cognitively aware and that instructors found the learning contracts, appraisals, reflective journals, and conferences helped them develop better rapport with their students. Other studies that are in conformity with the present study concerning the effectiveness of using metacognitive strategies include Narang and Saini (2013), Al-Besher, (2012), Azevedo (2005), Wong and law (2002), Nietfeld and Shraw (2002), Thiede, Anderson, and Therriault (2003).

However, the results of this study contradict the findings of Azizi, Nemati, and Estahbanati (2017) where they found that metacognitive strategy categories such as planning, monitoring, and self-awareness did not predict students' writing performance. However, their study aims to investigate the metacognitive awareness of writing strategy use among Iranian EFL learners and its impact on their writing performance. Dobson (2016) construes that even though there are evidences that highlight the impact of metacognition training on the construction of written texts, not all metacognitive experiences influence production of written communication.

\section{Conclusion and Implications}

This study began with the proposition that teaching meta-cognitive learning strategies could improve the student writing proficiency. The instruction was for a period of twelve weeks. During this time, the researcher employed meta-cognitive learning strategies and taught the participants in the experimental group how to utilize metacognitive strategies in their writing skill. The participants in the control group, on the other hand, did not get any instruction on the use of these strategies during their writing skill practice. After the posttest, the results indicated that the instruction of meta-cognitive learning strategies improved the learners' writing skill. The writing proficiency of the experimental group who used the meta-cognitive learning strategies exceeded that of the control group. The recent study identified metacognition as a significant determinant of English written proficiency.

The implementation of metacognitive tasks means moving certain responsibilities to learners, which in turn might raise their pressure, precisely on the less proficient ones. It is therefore proposed that vivid and straightforward instructions and modeling, and monitored practice should be readily available. When teaching EFL writing metacognitively, the instructor should be encouraging and motivate learners and pay attention to their voices from distinct venues to control and access the teaching strategies employed. In addition, the situation of taking metacognition into practice might be disrupted by cultural factors and require more findings in this aspect. Promoting students' metacognitive awareness in an integrative EFL writing class implies that the process and the outcome of approaches are not regarded as negative but complementary (Mbato, 2013). It also helps 
teachers and students to access and regulate their efforts, thus making an EFL writing class more effective. However, it is recommended that as students' knowledge of and familiarity with methodologies increase, genre approaches can also be intertwined as, in the words of Byrnes (2012, p. 205), "a continuation of product approaches" to link writing with distinguished social contexts. Writing performance is paramount though a challenging academic skill for secondary and postsecondary students to perfect. An exhaustive assessment of students' writing skills, with emphasis on persuasive writing tasks, gives more insight into the developmental cognitive processes of writing performance.

\section{References}

Al-Bahrani, M. A. (2014). A qualitative exploration of help-seeking process. Advances in Applied Sociology, 4(07), 157-172. https://doi.org/10.4236/aasoci.2014.47020

Al-Besher, K. (2012). Developing the writing skills of ESL students through the collaborative learning strategy (Published doctoral dissertation). Newcastle University.

Aliweh, A. M. (2011). The effect of electronic portfolios on promoting Egyptian EFL college students' writing competence and autonomy. Asian EFL Journal, 13(2), 90-132.

Al-Sawalha, A. M. S., \& Chow, T. V. F. (2012). The effects of proficiency on the writing process of Jordanian EFL University students. Academic Research International, 3(2), 379.

Amani, S. (2014). Metacognitive Strategy Instruction and Pre-task Planning: Impact on L2 Argumentative Writing Ability. Published doctoral dissertation, Auckland University.

Ashman, A. F., \& Conway, R. N. (2017). Using cognitive methods in the classroom. Routledge. 1(2), 210-220. https://doi.org/10.4324/9781315271019

Azizi, M., Nemati, A., \& Estahbanati, N. (2017). Meta-cognitive awareness of writing strategy use among iranian EFL learners and its impact on their writing performance. International Journal of English Language \& Translation Studies, 5(1), 42-51.

Bani-Khaled, T. A. A. D. (2013). Learning English in difficult circumstances: The case of north Badiah disadvantaged schools in Jordan. Australian Journal of Basic and Applied Sciences, 7(8), 269-284.

Beauchamp, G., \& Kennewell, S. (2010). Interactivity in the classroom and its impact on learning. Computers \& Education, 54(3), 759-766. https://doi.org/10.1016/j.compedu.2009.09.033

Bitchener, J., Young, S., \& Cameron, D. (2005). The effect of different types of corrective feedback on ESL student writing. Journal of Second Language Writing, 14(3), 191-205. https://doi.org/10.1016/j.jslw.2005.08.001

Briesmaster, M., \& Etchegaray, P. (2017). Coherence and cohesion in EFL students' writing production: The impact of a metacognition-based intervention. Íkala, revista de lenguaje y cultura, 22(2), 183-202. https://doi.org/10.17533/udea.ikala.v22n02a02

Byrnes, H. (2012). Conceptualizing FL writing development in collegiate settings: A genre-based systemic functional linguistic approach. In L2 writing development: Multiple perspectives (pp. 190-218). De Gruyter Mouton Berlin. https://doi.org/10.1515/9781934078303.191

Chamot, A. U., \& O'malley, J. M. (1994). The CALLA handbook: Implementing the cognitive academic language learning approach. Massachusetts: Addison-Wesley Publishing Company.

Chutichaiwirath, K., \& Sitthitikul, P. (2017). The metacognitive awareness of reading strategies in Thai EFL learners. Journal of Nusantara Studies, 2(2), 1-14. https://doi.org/10.24200/jonus.vol2iss2pp1-14

Collins, A., Brown, J. S., \& Newman, S. E. (1989). Cognitive apprenticeship: Teaching the crafts of reading, writing, and mathematics. Knowing, learning, and instruction: Essays in honor of Robert Glaser, 18, 32-42.

Corkery, F. (2014). An analysis of year 8 poor comprehenders' responses to the PAT Reading Comprehension test: a thesis submitted in partial fulfilment of the requirements for the degree of Master of Literacy Education at Massey University, Palmerston North, New Zealand (Published doctoral dissertation). Massey University.

Danielson, C. (2013). The framework for teaching evaluation instrument, 2013 instructionally focused edition. Princeton, NJ: The Danielson Group. Retrieved from http://www.danielsongroup.org/framework

Dobson, D., \& Dobson, K. S. (2016). Evidence-based practice of cognitive-behavioral therapy. Guilford Publications, 5(1), 195-210. 
Downing, K., Ho, R., Shin, K., Vrijmoed, L., \& Wong, E. (2007). Metacognitive development and moving away. Educational Studies, 33(1), 1-13. https://doi.org/10.1080/03055690600850347

Flavell, J. H. (1979). Metacognition and cognitive monitoring: A new area of cognitive-developmental inquiry. American psychologist, 34(10), 906. https://doi.org/10.1037/0003-066X.34.10.906

Flower, L. (1989). Problem-solving strategies for writing. Orders, Harcourt Brace Jovanovich, 7555 Caldwell Ave., Chicago, IL 60648.

Goh, C., \& Taib, Y. (2006). Metacognitive instruction in listening for young learners. ELT Journal, 60(3), 222-232. https://doi.org/10.1093/elt/ccl002

Graham, S., \& Harris, K. R. (2006). Strategy instruction and the teaching of writing. Handbook of writing research, 5, 187-207.

Graham, S., \& Perin, D. (2007). Writing Next-Effective strategies to improve writing of adolescents in middle and high schools. Profile Issues in TeachersProfessional Development, 1(3), 12.

Gustilo, L. E. (2013). An analysis of writer's performance, resources, and idea generation processes: The case of Filipino engineering students. Language Testing in Asia, 3(1), 2. https://doi.org/10.1186/2229-0443-3-2

Harris, K. R., Graham, S., \& Mason, L. H. (2003). Self-regulated strategy development in the classroom: Part of a balanced approach to writing instruction for students with disabilities. Focus on Exceptional Children, $35(7), 1$.

Hartman, H. J. (2015). Engaging adolescent students' metacognition through webquests: a case study of embedded metacognition. In Metacognition: Fundaments, Applications, and Trends (pp. 135-166). Springer, Cham.

Hertzog, C., \& Dunlosky, J. (2004). Aging, metacognition, and cognitive control. The psychology of learning and motivation: Advances in research and theory, 45, 215-251. https://doi.org/10.1016/S0079-7421(03)45006-8

Hirvela, A. (1997). "Disciplinary portfolios" and EAP writing instruction. English for Specific Purposes, 16(2), 83-100. https://doi.org/10.1016/S0889-4906(96)00037-3

Hong-Nam, K., \& Leavell, A. G. (2006). Language learning strategy use of ESL students in an intensive English learning context. System, 34(3), 399-415. https://doi.org/10.1016/j.system.2006.02.002

Javed, F. (2013). Teaching Language Learning Strategies to English as Second Language (ESL) Learners. Research Journal of Anguage \& Iterature, 2, 2.

Johnson, D. W. (1991). Cooperative learning: increasing college faculty instructional productivity. Ashe-Eric higher education report no. 4, 1991. ASHE-ERIC Higher Education Reports, George Washington University, one Dupont Circle, suite 630, Washington, DC 20036-1183.

Kasper, W., Konstantinides, S., Geibel, A., Olschewski, M., Heinrich, F., Grosser, K. D., \& Kienast, J. (1997). Management strategies and determinants of outcome in acute major pulmonary embolism: Results of a multicenter registry. Journal of the American College of Cardiology, 30(5), 1165-1171. https://doi.org/10.1016/S0735-1097(97)00319-7

Knapp, P., \& Watkins, M. (2005). Genre, text, grammar: Technologies for teaching and assessing writing. UNSW Press, 170-185.

Kraus, R. M. (2007). Cognitive and motivational strategies for reaching individuals with learning disabilities: Developing a toolkit for practitioners (Published doctoral dissertation). Union Institute and University.

Lopera Medina, S. (2012). Effects of strategy instruction in an EFL reading comprehension course: A case study. Profile Issues in TeachersProfessional Development, 14(1), 79-89.

Mbato, C. L. (2013). Facilitating EFL learners' self-regulation in reading: Implementing a metacognitive approach in an Indonesian higher education context (Published doctoral dissertation). Southern Cross University.

Meyer, O. (2015). Towards quality CLIL: successful planning and teaching strategies. PULSO. Revista de Educación, (33), 11-29.

Mohamed, A. F., \& Rashid, R. A. (2017a). The metadiscourse markers in good undergraduate writers' essays corpus. International Journal of English Linguistics, 7(6), 213-220. 
Mohamed, A. F., \& Rashid, R. A. (2017b). Organisational discourse markers in ESL students' essays: A study of metadiscourse. International Journal of Academic Research in Progressive Education and Development, 6(3), 226-237.

Mohammed, Q., \& Rashid, R. A. (2017). Reading comprehension difficulties among EFL learners: The case of first and second year students at Yarmouk University in Jordan. Arab World English Journal, 8(3), 421-431.

Mugableh, A., \& Ibrahim, A. (2016). Jordanian Non-Native English Speaker's Academic Discourse Socialization and Linguistic Development in Oral Academic Presentations in Malaysia (Published doctoral dissertation). Universiti Sains Islam Malaysia.

Muslim, I. M. (2014). Helping EFL students improve their writing. International Journal of Humanities and Social Science, 4(2), 105-112.

Muthanna, A. (2016). Teaching and learning EFL writing at Yemeni Universities: A review of current practices. In Teaching EFL Writing in the 21st Century Arab World (pp. 221-243). Palgrave Macmillan, London. https://doi.org/10.1057/978-1-137-46726-3_9

Narang, D., \& Saini, S. (2013). Metacognition and academic performance of rural adolescents. Studies on Home and Community Science, 7(3), 167-175. https://doi.org/10.1080/09737189.2013.11885409

Nguyen, H., Shen, Z., Gu, X., Subbiah, S., \& Wilkes, J. (2013, June). AGILE: elastic distributed resource scaling for infrastructure-as-a-service. In ICAC (Vol. 13, pp. 69-82).

Nietfeld, J. L., \& Schraw, G. (2002). The effect of knowledge and strategy training on monitoring accuracy. The Journal of Educational Research, 95(3), 131-142. https://doi.org/10.1080/00220670209596583

Penuel, W. R., Riel, M., Krause, A., \& Frank, K. A. (2009). Analyzing teachers' professional interactions in a School as social capital: A social network approach. Teachers College Record, 111(1), 124-163.

Pittinsky, M. L. (2008). Smart by (perceived) association: Cognitive social networks and teacher academic judgments (Published doctoral dissertation). Columbia University, 47-55

Powell, K. C., \& Kalina, C. J. (2009). Cognitive and social constructivism: Developing tools for an effective classroom. Education, 130(2), 241-251.

Qinghua, L. (2010). The impact of portfolio-based writing assessment on EFL writing development of Chinese learners. Chinese Journal of Applied Linguistics, 33(2). Foreign Language Teaching \& Research Press.

Rahimi, M., \& Katal, M. (2012). The role of metacognitive listening strategies awareness and podcast-use readiness in using podcasting for learning English as a foreign language. Computers in Human Behavior, 28(4), 1153-1161. https://doi.org/10.1016/j.chb.2012.01.025

Shazia, S. (2014). Self-concept, learning styles, study habits and academic achievement of adolescents in kashmir: A study on psychological variables and academic achievement of adolescents in Kashmir. Anchor Academic Publishing (aap_verlag), 165-180.

Stracke, E. (2016). Language learning strategies of Indonesian primary school students: In relation to self-efficacy beliefs. System, 60, 1-10. https://doi.org/10.1016/j.system.2016.05.001

Taggar, S., \& Neubert, M. J. (2008). A cognitive (attributions)-emotion model of observer reactions to free-riding poor performers. Journal of Business and Psychology, 22(3), 167-177. https://doi.org/10.1007/s10869-008-9058-0

Thiede, K. W., Anderson, M., \& Therriault, D. (2003). Accuracy of metacognitive monitoring affects learning of texts. Journal of educational psychology, 95(1), 66. https://doi.org/10.1037/0022-0663.95.1.66

Wei, Z., Shang, H., \& Briody, P. (2012). The Relationship between English writing ability levels and EFL learners' metacognitive behaviour in the writing process. International Journal of Academic Research in Progressive Education and Development, 1(4), 154-180.

Wong, C. S., \& Law, K. S. (2002). The effects of leader and follower emotional intelligence on performance and attitude: An exploratory study. The Leadership Quarterly, 13(3), 243-274. https://doi.org/10.1016/S1048-9843(02)00099-1

Woods, P. (2006). Successful writing for qualitative researchers. Psychology Press, 85-97. https://doi.org/10.4324/9780203001721 
Zumbrunn, S., Tadlock, J., \& Roberts, E. D. (2011). Encouraging self-regulated learning in the classroom: A review of the literature. Metropolitan Educational Research Consortium (MERC), 1-28.

\section{Copyrights}

Copyright for this article is retained by the author, with first publication rights granted to the journal.

This is an open-access article distributed under the terms and conditions of the Creative Commons Attribution license (http://creativecommons.org/licenses/by/4.0/). 